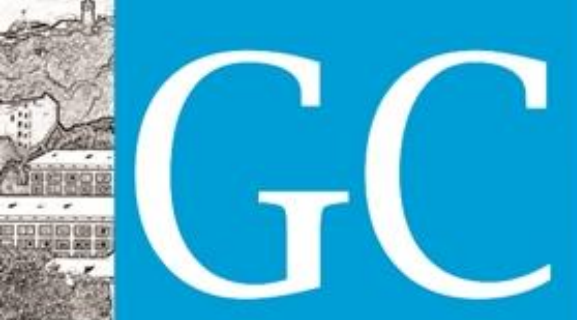

Revista Nacional de

Gerenciamento de Cidades

\title{
Avaliação do Padrão de Viagem de Alunos da Etec de Assis
}

Evaluation Of The Travel Pattern Of The Students Of The Assis' Etec

Evaluación Del Estándar De Viaje De Los Alumnos De La Etec De Assis

Fábio Albert Basso

Mestrando, UNESP, Brasil fabioalbertbasso@yahoo.com.br

\author{
João Victor Garcia de Senna \\ Aluno Especial, UNESP, Brasil \\ joaovictorsenna@hotmail.com
}

Renata Cardoso Magagnin

Professora Doutora, UNESP, Brasil.

renatamagnanin@unesp.br 


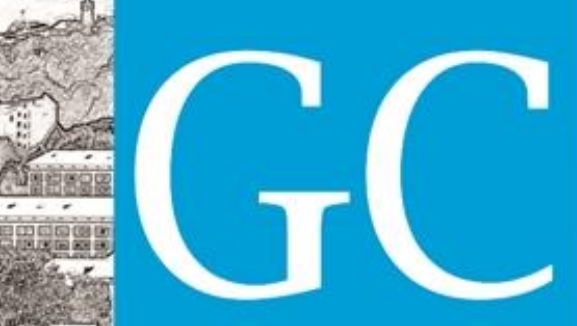

ISSN 2318-8472

Revista Nacional de Gerenciamento de Cidades

chegar à instituição de ensino (Figura 3). Esse valor pode estar associado ao número de alunos (20) que residem em cidades vizinhas ou na zona rural do município. Em relação a volta para casa, o aumento desse percentual pode ser explicado pela parcela de alunos que utiliza o carro na ida, porém volta para o seu destino a pé.

Ainda na Figura 3 pode-se destacar uma predominância de deslocamentos na faixa de até 15 minutos (aproximadamente $50 \%$ dos deslocamentos), que é um tempo aceitável para o deslocamento a pé, associado ao tamanho do município.

Figura 3: Tempo de deslocamento nos trajetos de ida e volta da escola

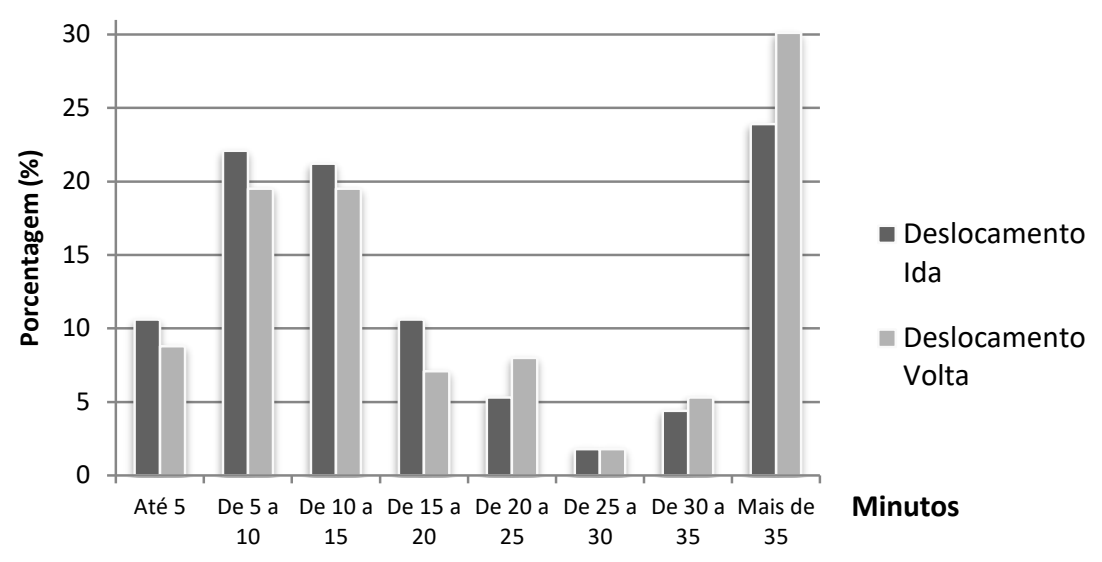

Fonte: Autores, 2018.

O mapa apresentado na Figura 4 permite espacializar as informações apresentadas na Figura 3, em minutos. Os dados mostram que a ETEC atrai alunos de diferentes regiões da cidade de Assis, para formação tradicional do ensino médio. 


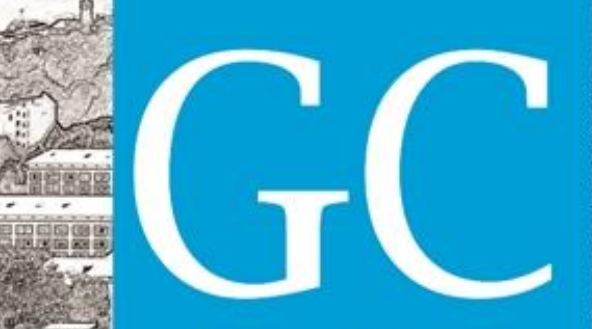

\section{Revista Nacional de}

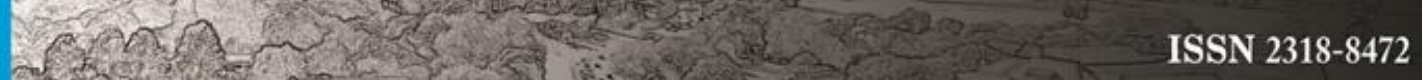

Gerenciamento de Cidades

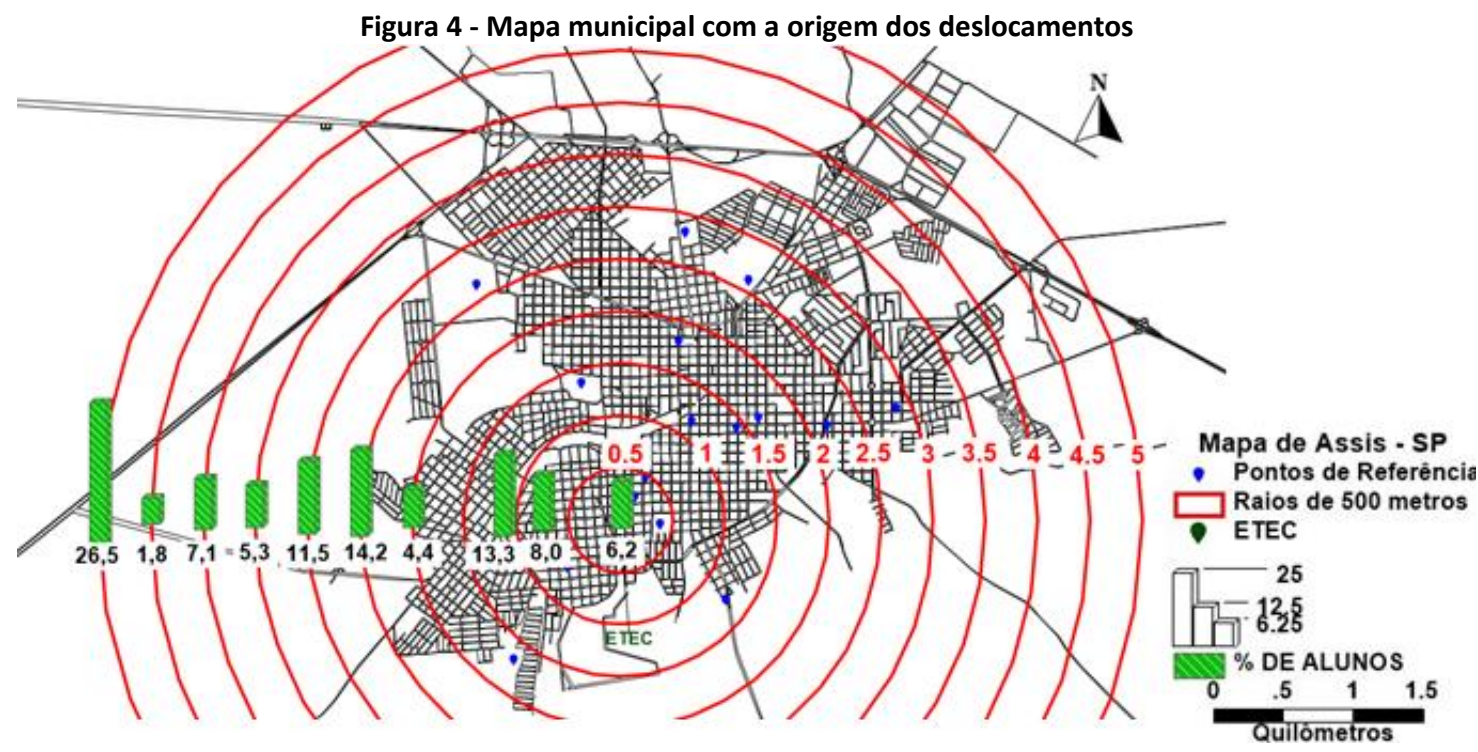

Fonte: Autores, 2018.

Considerando o raio de abrangência de 1600 metros proposto por Guimarães (2004 apud NEVES, 2015) e o raio de 3000 metros estabelecido por Gouvêa (2008 apud NEVES, 2015) para deslocamento de alunos para escolas de Ensino Médio, verifica-se que a porcentagem de alunos com suas residências dentro das faixas estabelecidas na literatura, em Assis corresponde a $28 \%$ dos alunos com moradia distante até $1600 \mathrm{~m}$ e $58 \%$ de alunos até $3000 \mathrm{~m}$ (Figuras 4 e 5 ).

Os valores encontrados estão longes daqueles estabelecidos no Guia LEED (U.S. GREEN BUILDING COUNCIL, 2011), que indica que $50 \%$ das residências devem estar localizadas em uma distância de caminhada de até $1600 \mathrm{~m}$ dos estabelecimentos escolares, para facilitar o deslocamento por meios ativos. Outro fato relevante é que $26,5 \%$ dos estudantes estão localizados a mais de $5500 \mathrm{~m}$ da ETEC, fator esse que contribui fortemente para aumentar o número de deslocamentos realizados por automóveis ou por ônibus/transporte escolar.

Figura 5: Percentual de alunos com moradia dentro de faixas estabelecidas na literatura

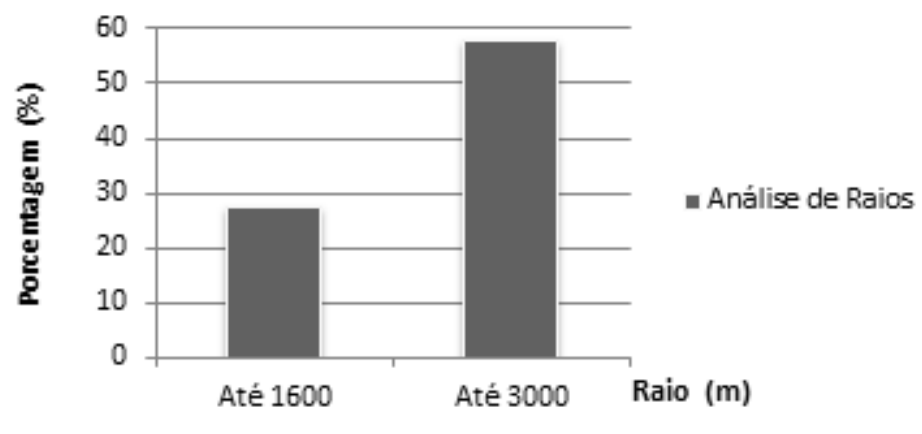

Fonte: Autores, 2018. 


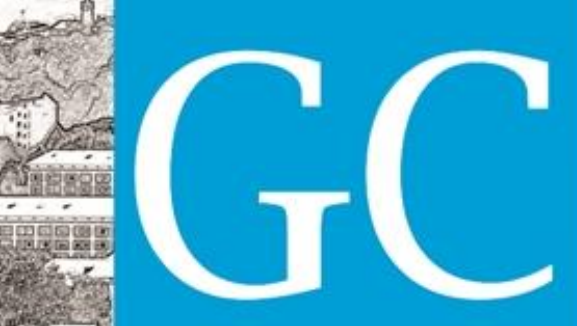

\section{Revista Nacional de} Gerenciamento de Cidades

Com relação a essa distância de moradia, pode-se ainda associar alguns problemas relacionados a cansaço físico pela demora do trajeto no dia-a-dia, inadequação de infraestrutura, maior custo no transporte, lotação e demora na espera, pois normalmente para regiões mais afastadas, não há uma grande quantidade de transporte público disponível.

A análise da questão que avaliava a possibilidade ou desejo de mudança no modo de transporte utilizado pelos estudantes revelou que $42 \%$ dos alunos acenaram positivamente para essa alteração, ou seja, se tivessem condições, mudariam seu modo de deslocamento para a instituição de ensino (Figura 6). No entanto ao associar os resultados da pergunta anterior com a questão sobre para qual modo de transporte que seria a mudança, observa-se que a maioria gostaria de utilizar o automóvel. Essa resposta mostra o quanto as discussões sobre as políticas públicas de mobilidade urbana sustentável ainda estão distantes da sociedade e principalmente dos jovens.

Figura 6: Modo escolhido pelos estudantes caso tivessem condições de mudar seu meio de transporte

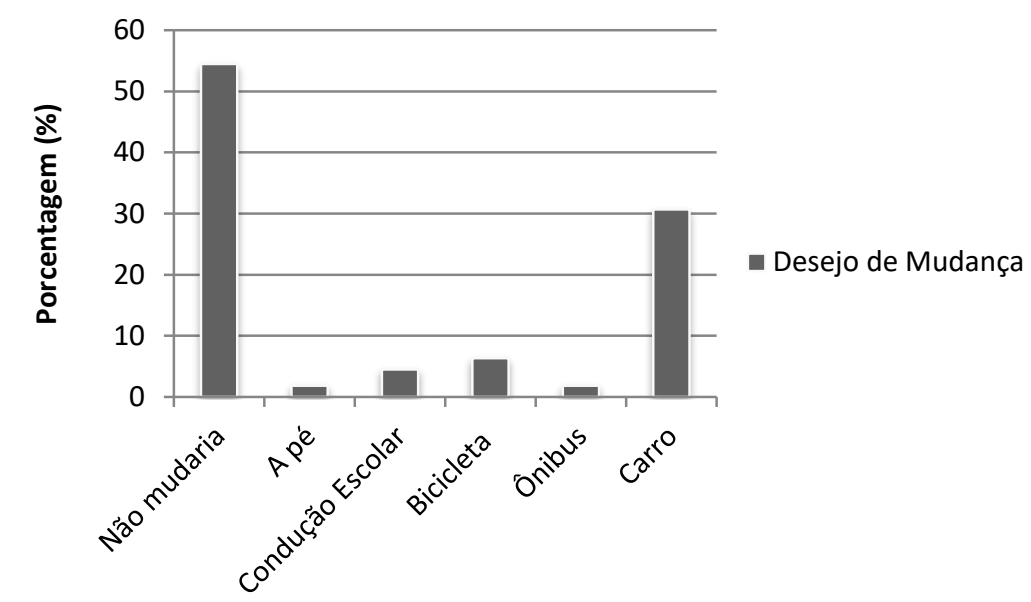

Fonte: Autores, 2018.

Em relação aos motivos que interferem nessa mudança, os resultados mostraram que das 38 respostas a preferência por utilizar o automóvel está associada ao tempo, distância e comodidade ou conforto (Figura 7). 


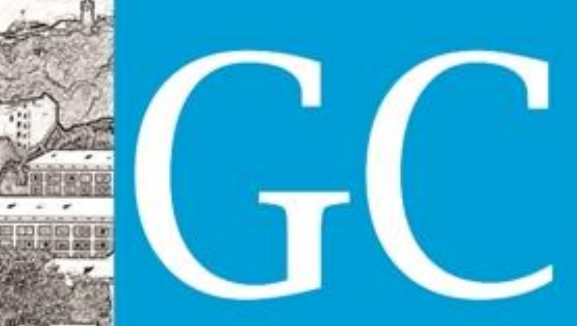

\section{Revista Nacional de}

Gerenciamento de Cidades

Figura 7: Principais fatores que desencadeiam desejos de mudança no modo de deslocamento

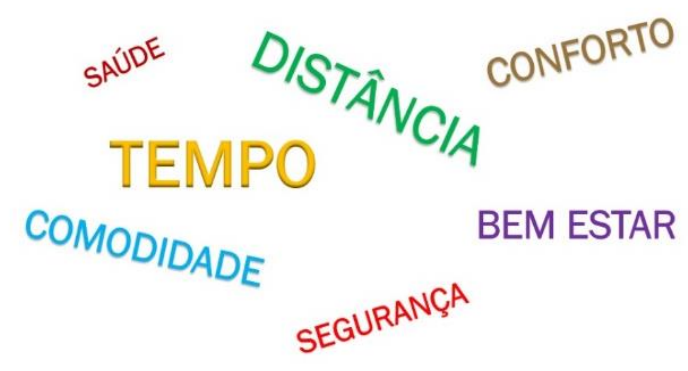

Fonte: Autores, 2018.

Para identificar onde estava concentrado o fluxo de alunos no entorno escolar nos períodos de entrada e saída os dados foram especializados em 4 mapas apresentados nas Figuras 8 a 10. A Figura 8 mostra fluxo de alunos incluindo todos os modos de transportes no período de chegada à instituição de ensino. As Ruas Benedito Lucci, Olavo Bilac e Sr. do Bonfim são as mais congestionadas e que provavelmente ocasionam problemas a quem passa na região no horário de início das aulas, com um fluxo de 30 alunos ou mais passando por elas.

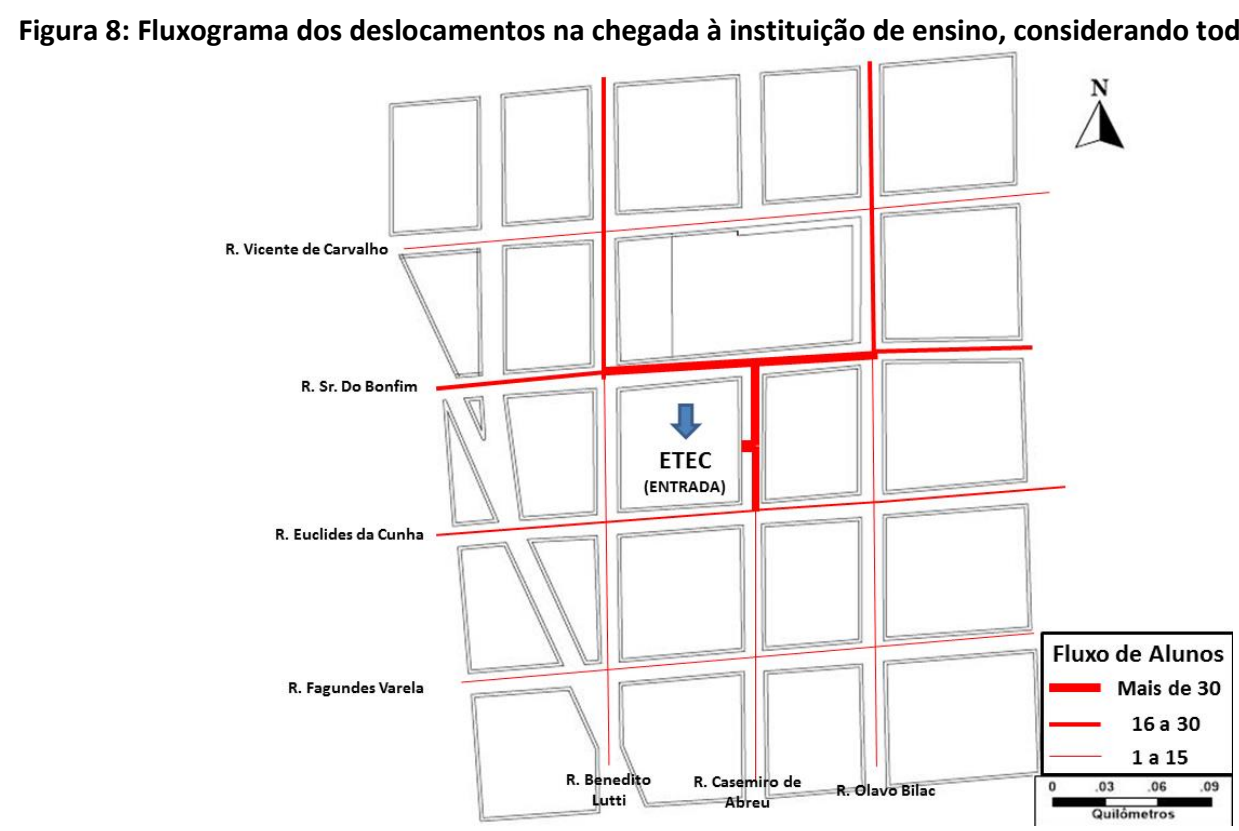

Fonte: Autores, 2018.

No período de término das aulas, merece destaque as ruas Olavo Bilac e Sr. do Bonfim, uma vez que o fluxo de viagem é maior do que 50 alunos (Figura 9). Estes resultados poderiam ser utilizados como parâmetros para reorganização do trânsito local, pelos planejadores urbanos e de trânsito do município, e assim estabelecer diretrizes para a região, como por exemplo, 


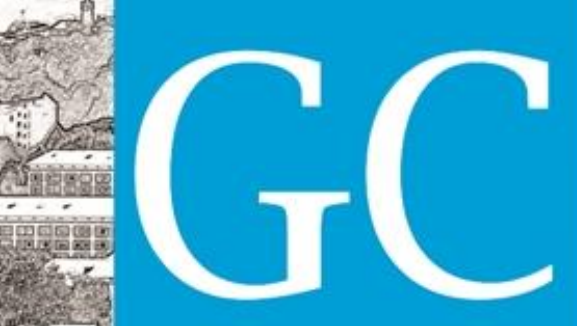

\section{Revista Nacional de}

Gerenciamento de Cidades

alteração de largura e sentido das vias, velocidades máximas permitidas, áreas de estacionamento e sinalização.

Figura 9: Fluxograma dos deslocamentos na saída da instituição de ensino, considerando todos os modais

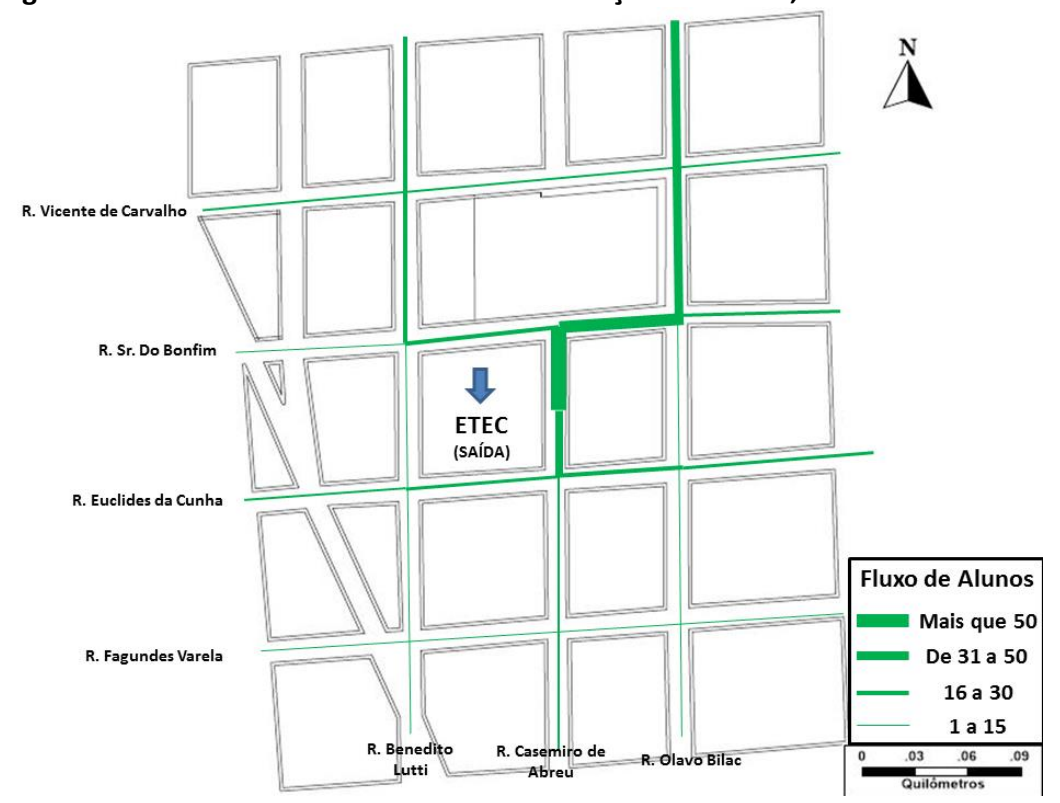

Fonte: Autores, 2018.

Com relação a análise apenas do fluxo de pedestres observa-se que tanto no período de chegada quanto na saída da instituição de ensino, às Ruas Benedito Lucci, Olavo Bilac e Sr. do Bonfim são as mais utilizadas (Figuras 10 e 11). Cabe ressaltar que como já discutido anteriormente, na saída, o fluxo de pedestres é maior devido aos estudantes que vêm de automóvel e retornam ao seu destino caminhando, o fluxo em algumas vias é maior. 


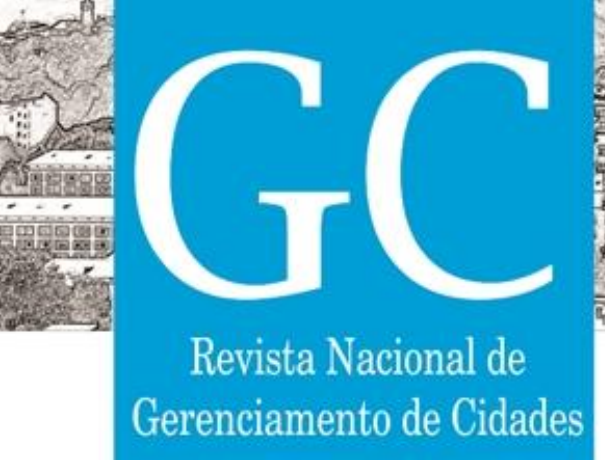

NANYA, Luciana Mayumi; SANCHES, Sueli da Penha. Proposta de Instrumento para Auditoria e Avaliação da Caminhabilidade. XXIX Congresso na Clonal de Pesquisa em Transporte da Anpet, Ouro Preto, 9 a 13 de novembro de 2015. Modelos e Técnicas de Planejamento de Transportes Planej. Cicloviário e da Circ. de Pedestres. Programa de Pós-graduação em Engenharia Urbana Universidade Federal de São Carlos, 2015. Disponível em: <http://anpet.org.br/xxixanpet/anais/documents/AC559.pdf>. Acesso em: 22 de setembro de 2016.

REIS, Manoel de Andrade e Silva. Mobilidade urbana: um desafio para gestores públicos. Cadernos FGV projetos cidades inteligentes e mobilidade urbana. São Paulo, 2017.

SPAGNUOLO, Augusto Yuji Nojima; MAGAGNIN, Renata Cardoso (2017). Avaliação Do Padrão De Viagens Dos Alunos De Escola Técnica Estadual. In: Simpósio Nacional de Gestão e Engenharia Urbana, 1, São Carlos, 2017. Anais... Universidade Federal de São Carlos, 2017.

TRANSPORTATION RESEARCH BOARD - TRB. National Research Council. Highway Capacity Manual - HCM. Washington, DC, v. 113, 2000.

U.S. GREEN BUILDING COUNCIL. 2011 LEED for Homes Award Recipients Announced. Toronto, 2011. 